[A. Tunei Lin, B. Elke Goos, C. Uwe Riedel, A sectional approach for biomass: Modelling the pyrolysis of cellulose, Fuel Processing Technology 115 (2013) 246-253.]

The original publication is available at www.elsevier.com

http://dx.doi.org/10.1016/j.fuproc.2013.03.048 


\title{
A sectional approach for biomass: Modelling the pyrolysis of cellulose
}

\author{
Tunei Lin ${ }^{1}$, Elke Goos ${ }^{2}$, and Uwe Riedel ${ }^{3}$ \\ Institute of Combustion Technology, German Aerospace Center (DLR), Stuttgart, Germany
}

\begin{abstract}
We present the adaptation of the sectional model approach to the pyrolysis of cellulose, $\left(\mathrm{C}_{6} \mathrm{H}_{10} \mathrm{O}_{5}\right)_{\mathrm{n}}$. Cellulose is the major component of lignocellulosic biomass. Due to its longitudinal structure, cellulose is characterized by one-dimensional chains composed of a varying number of cellobiose molecules, $\mathrm{C}_{12} \mathrm{H}_{22} \mathrm{O}_{11}$. Fragments of those chains with similar mass are grouped into size classes (BINs) determined by characteristic numbers of cellobiose monomers. During the pyrolysis of cellulose, reaction temperatures of more than approximately $500 \mathrm{~K}$ (depending on the heating rate) initiate bond dissociation within the chains, i.e. between cellobiose units, resulting in smaller chain fragments. We have developed a new reaction scheme for the pyrolysis of cellulose based on existing models from literature. However, we present the sectional approach as new concept for modelling the degradation (depolymerisation) step. Our model comprises the degradation of solid cellulose, its devolatilisation to either glucose or to tars (e.g. levoglucosan) including primary gaseous products (e.g. $\mathrm{CO}$ and $\mathrm{CO}_{2}$ ), the formation of char and water from various pathways, as well as secondary gas-phase reactions. For the cellulose degradation, we propose a kinetic data set of $A=2.2 \cdot 10^{13} \mathrm{~s}^{-1}$ and $E_{\mathrm{A}}=225.9 \mathrm{~kJ} / \mathrm{mol}$ for the dissociation of a single glycosidic bond. The model was tested via reactor simulations. Cellulose is pyrolysed at a constant heating rate $(1,10,15$, and $150 \mathrm{~K} / \mathrm{min}$ ) from $323 \mathrm{~K}$ up to a preset final temperature of $1073 \mathrm{~K}$. Our simulations show good agreement with two different experimental data sets from literature for all heating rates.
\end{abstract}

\section{Nomenclature}

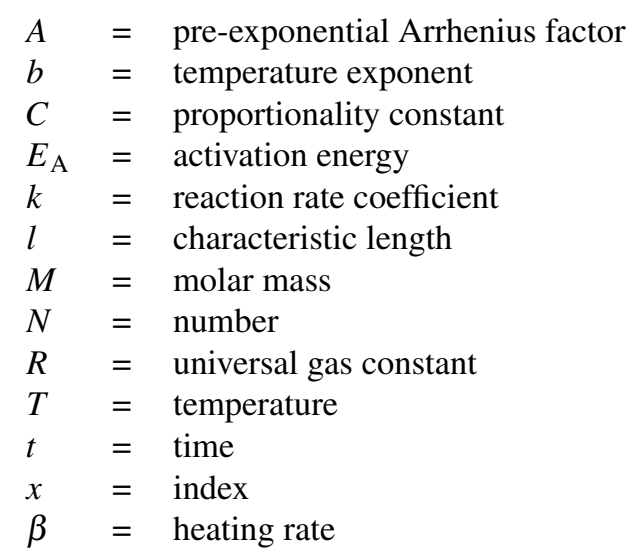

\footnotetext{
${ }^{1}$ Ph.D. Student, Chemical Kinetics Department, Pfaffenwaldring 38-40, 70569 Stuttgart, Germany, tunei.lin@dlr.de

${ }^{2}$ Senior Scientist, Chemical Kinetics Department, Pfaffenwaldring 38-40, 70569 Stuttgart, Germany, elke.goos@dlr.de

${ }^{3}$ Professor, Head of Chemical Kinetics Department, Pfaffenwaldring 38-40, 70569 Stuttgart, Germany, uwe.riedel@ dlr.de
} 


\section{Introduction}

One likely candidate as a renewable alternative to fossil fuels is lignocellulosic biomass. The dry material of plants and trees consists primarily of three major components: cellulose, hemicellulose (also known as polyose), and lignin. Depending on the type of feedstock (hardwood, softwood, or agricultural), the constituent fractions can vary strongly, but characteristic trends can be observed [1-4]. Generally, dry mass of lignocellulosic biomass roughly comprise 40-50\% cellulose, 20-30\% hemicellulose, and 20-35\% lignin. Several other components (starch, ash, pectins, lipids, and other trace species) can exist in negligible quantities in hard- and softwoods, whereas the quantities in agricultural plants, e.g. switchgrass, can be significant. Compositions of various lignocellulosic biomass feedstock were widely investigated and can be found in e.g. $[1,5,6]$. However, their actual composition has a significant impact on biomass pyrolysis and its product distribution. Good overviews of wood and biomass pyrolysis can be found in [7,8]. Worasuwannarek and co-workers [3, 4] investigated the pyrolysis of three different types of lignocellulosic biomass (rice straw, rice husk, and corncob) and they found that water is the main product for all the samples. This is due to the high oxygen content in lignocellulosic biomass. Further products during pyrolysis include $\mathrm{CO}, \mathrm{CO}_{2}, \mathrm{CH}_{4}$, tars (e.g. levoglucosan $\mathrm{C}_{6} \mathrm{H}_{10} \mathrm{O}_{5}$ ), and solid residues (char). However, the pyrolysis of pure cellulose produces mostly tars.

\subsection{Cellulose}

The focus of this paper is on cellulose. It is the major, and by far the most investigated, component of lignocellulosic biomass. Cellulose is a polysaccharide produced by plants during photosynthesis. Cellulose covers approximately one third of all plant matter making it the most abundant organic compound on earth. The bundles of cellulose fibres serve as the structural component of the primary cell walls of plants and trees. Its potential as an alternative fuel source over lignocellulosic biomass is increased by the fact that it is indigestible by human beings. Hence, unlike starch (a main constituent of many agricultural plants), it does not interfere directly with the human food chain. In practice, the conversion of cellulose to biofuels, e.g. cellulosic ethanol, is under investigation $[5,7,9-11]$. However, it must be considered that inedible energy plants still require agricultural area and water resources and compete, therefore, with food production.

Cellulose has the molecular formula $\left(\mathrm{C}_{6} \mathrm{H}_{10} \mathrm{O}_{5}\right)_{n}$ and its chemical composition corresponds to a polymer of typically between several hundred to over ten thousand D-glucopyranose monomers. These are linked by 1,4 '- $\beta$ glycosidic bonds with an alternate rotation of $180^{\circ}$ forming linear chains (see Fig. 1). Depending on chain length, i.e. number of monomers or degree of polymerization, the properties of cellulose can vary immensely. Unlike in the structure of the polysaccharide starch, which has the same molecular formula but its glucopyranose units are linked with $\alpha$-glycosidic bonds, no branches or coils occur. The numerous intra- and intermolecular hydrogen bonds of this structure help to create a robust, rigid crystalline structure [9, 12]. Four general types of cellulose can be distiguished, namely cellulose I, II, III, and IV. Cellulose I is the one occuring in nature and consists out of two crystalline forms $\mathrm{I} \alpha$ (e.g. dominant in some algae and bacteria) and $\mathrm{I} \beta$ (e.g. dominant in wood or cotton) $[13,14]$. Up to temperatures of 300-400 K its crystalline structure is dominated by intrachain hydrogen bonds. However, at $450-550 \mathrm{~K}$ it transforms to an amorphous and more reactive structure characterised by (weaker) interchain hydrogen bonds [12,15]. After this initial conversion step the degradation of (amorphous) cellulose chains occurs by bond dissociation between the monomer linkages. In order to consider this phenomena, we composed cellulose out of cellobiose units $\left(\mathrm{C}_{12} \mathrm{H}_{22} \mathrm{O}_{11}\right)$ in our model which is based on the early works of Haworth et al. [16, 17] and the recent work of Assary and Curtiss [18] (see Fig. 1).

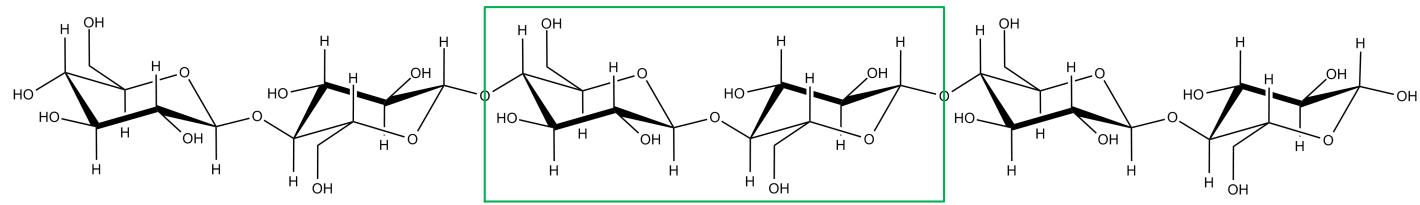

Figure 1. Chemical structure of cellulose $\left(\mathrm{C}_{6} \mathrm{H}_{10} \mathrm{O}_{5}\right)_{n}$ and cellobiose building block $\mathrm{C}_{12} \mathrm{H}_{22} \mathrm{O}_{11}(\mathrm{box})$. 


\subsection{Pyrolysis}

There are three ways of thermally converting biomass into technically more usable forms of energy: combustion, gasification, and pyrolysis. Combustion, however, is not considered as a promising alternative because of environmental issues. Biological conversion such as fermentation or digestion is also widely field-tested, especially in rural areas. These processes mostly yield single products (ethanol, biogas with a very high methane content). However, their relatively long process times, usually days or weeks, make them economically inferior to thermal conversion [10].

The main goal of gasification is the production of fuel gases (yields in order of magnitude of $80 \%$ ), mainly of synthesis gas (syngas), a mixture of $\mathrm{CO}$ and $\mathrm{H}_{2}$. Hence, the process takes place under relatively high temperatures, i.e. above $1000 \mathrm{~K}$, in order to increase the gas yield. A proportion of the required energy is provided internally by exothermic reactions of parts of the feedstock, which contains an oxygen component itself. Gasification, as well as combustion, is always initiated by pyrolysis and requires total or partial oxidation as a following step.

During pyrolysis, the feedstock is thermally decomposed under the exclusion of external oxygen. These conditions and moderate process temperatures require an external thermal source often achieved by constantly heating the feedstock to a designated temperature of approximately $1000 \mathrm{~K}$. As an example, Worasuwannarek et al. [3] report that the pyrolysis of cellulose starts at a temperature of around $450 \mathrm{~K}$ and is completed at around $875 \mathrm{~K}$.

Pyrolysis can be in general characterized by three main physical parameters: process temperature, residence time, and heating rate. Process temperatures of approximately 500-900 K favour the production of liquids (yields in order of magnitude of $75 \%$ ), i.e. bio-oil in case of biomass pyrolysis. However, gaseous and solid product yields are not negligible, i.e. at around $10 \%$. Pyrolysis at approximately $675 \mathrm{~K}$ and below is known as slow pyrolysis, as opposed to fast pyrolysis at approximately $775 \mathrm{~K}$. The long residence times of slow pyrolysis (in order of hours) compared to those of fast pyrolysis (in order of seconds) favours the production of carbonaceous residues (char). The heating rate is known to play an important role in influencing the product distribution. High heating rates, as used in fast pyrolysis, also minimize the production of solid residues. The process of fast pyrolysis is characterized by several essential steps. First, the solid feedstock is dried to a matter which contains less than $10 \%$ water. In order to heat up the dry material very rapidly, it needs to be rather finely grinded, typically to a particle size of less than $3 \mathrm{~mm}$. Hence, the feedstock is decomposed very quickly to produce mainly vapours and aerosols. Finally, these primary products are rapidly cooled to generate high amounts of bio-oil [10]. Since this liquid product facilitates transportation and storage, fast pyrolysis is of particular interest as an option to convert biomass into higher energy content materials. For commercial use, the resulting bio-oil can be converted to biofuels, e.g. via Fischer-Tropsch processes to BtL-fuel (Biomass to Liquid), heat, electricity or chemicals.

\section{Modelling}

\subsection{The Sectional Model Approach}

The sectional model approach is a concept originally developed for modelling the formation and degradation of aerosols [19]. Over the last decades, it has become an effective tool in modelling the formation of soot particles in combustion processes, e.g. [20-23]. The sectional approach distinguishes the species of interest in subsequent size and/or mass classes, so-called BINs. This classification takes into account that molecules of the same species class with different size and/or mass have different properties. The smallest BIN consists of one basic molecule, whereas the other subsequent pseudo species are composed out of multiple numbers of this building block.

To the authors' knowledge the sectional approach has so far not been adapted to thermal decomposition of lignocellulosic biomass, and cellulose respectively. In models from literature, cellulose is characterized as a lumped species. However, it is known that the properties of cellulose depend on chain length, i.e. number of monomers. By introducing transient species (BINs) to the model pathway, we were able to describe the phase change from solid cellulose samples to gaseous products during pyrolysis.

In our model, we chose cellobiose, $\mathrm{C}_{12} \mathrm{H}_{22} \mathrm{O}_{11}$, as the basic building block which also represents the smallest size class, $\mathrm{BIN}_{1}$. The number of cellobiose units in the pseudo species, $\mathrm{BIN}_{\mathrm{X}}$ is generally calculated by

$$
N_{\text {cellobiose }}=2^{x-1} .
$$

To wit, BIN 2 consists of two cellobiose building blocks, BIN 3 of four, and so on. We used 18 BIN classes in our model with the initial feedstock, cellulose, being represented by the largest pseudo species, $\mathrm{BIN}_{18}$. The number of 
pseudo species, $N_{\mathrm{BINs}}$, results from the characteristic size or length of the cellulose samples we wanted to include in our model, i.e. approximately $100 \mu \mathrm{m}$. It is given by

$$
l_{\text {sample }}=2^{N_{\text {BINs }}} \cdot l_{\text {glucose }}
$$

with the characteristic length of one glucose molecule $l_{\text {glucose }}=6 \AA$. The size classes of our model comprise a total molar mass range in the order of magnitude of $10^{2}-10^{7} \mathrm{~g} / \mathrm{mol}$. The molar mass of each BIN is obtained by

$$
M_{\mathrm{BIN}}=N_{\text {cellobiose }} \cdot M_{\text {cellobiose }}
$$

with $M_{\text {cellobiose }}=342 \mathrm{~g} / \mathrm{mol}$.

Apart from that, our model can be easily adapted to the actual size of cellulose samples in experiments by using a corresponding number of BINs.

\subsection{Reaction Mechanism}

Several kinetic models (experimentally determined or derived from simulations) for the thermal decomposition of lignocellulosic biomass, and the pyrolysis of cellulose respectively are published in literature, e.g. [2, 24-49]. A good overview of different model approaches is given e.g. in [48]. However, the Antal group pointed out that experimental results may differ from each other because of the use of different cellulose samples [42]. In all publications, cellulose decomposition is described by first order reactions. The various and rather different reaction rates all follow the classical Arrhenius approach:

$$
k(T)=A \cdot T^{b} \cdot \exp \left\{-\frac{E_{\mathrm{A}}}{R \cdot T}\right\} .
$$

Some authors claim that the reaction rate coefficients for cellulose pyrolysis should depend on its heating rate, e.g. [37] and suggest different kinetic data sets for low and high heating rates. However, this proposition was disproved by Y. C. Lin et al. [48]. Heating rate dependent rate coefficients are also questionable from a chemical kinetics point of view. Kinetic rate coefficients for elementary reactions such as bond dissociation depend only on temperature and pressure and they are unique within their uncertainties. Therefore, the activation energy should be closely correlated with the bond dissociation energy of the breaking bond.

The most widespread model for cellulose pyrolysis, to the present date, is still the classical reaction scheme by Broido, Shafizadeh, and co-workers [24-28] which was later modified by Bradbury et al. [29]. The so-called "Broido-Shafizadeh model" is illustrated in Fig. 2. These authors propose that cellulose reacts without mass loss to an intermediate form ("active cellulose") first. The actual decomposition takes place by two competing pathways. Either cellulose decomposes to volatiles and tars (levoglucosan), or to solid residues (char) and gaseous products (e.g. $\mathrm{CO}_{2}$, and water). However, this early work is critically discussed by Várhegyi et al. [40, 41] claiming that the Broido-Shafizadeh model is too simple in terms of chemical and physical phenomena.

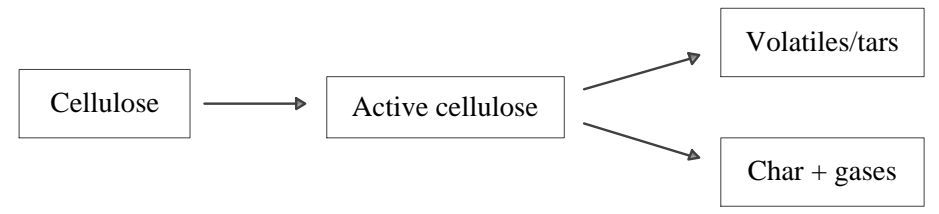

Figure 2. The Broido-Shafizadeh model - the classical reaction scheme for cellulose pyrolysis.

Figure 3 shows the reaction scheme for cellulose pyrolysis proposed in this paper. It takes into account the "Waterloo model" by Piskorz and co-workers [31,32] and the more recent works of Banyasz et al. [43, 44], and Mamleev et al. [45-47]. In our model, the solid cellulose sample can follow two different pathways. First, the degradation pathway forming depolymerised cellulose, and second, the anhydrocellulose pathway producing char and water. Continuous bond dissociation - leading to cellulose fragments with a low degree of polymerisation (DP) - is followed by the devolatilisation scheme. This includes two competing pathways, the production of an intermediate species and the transglycosylation pathway to tars (levoglucosan). Both pathways eventually lead to the production of secondary gases. 


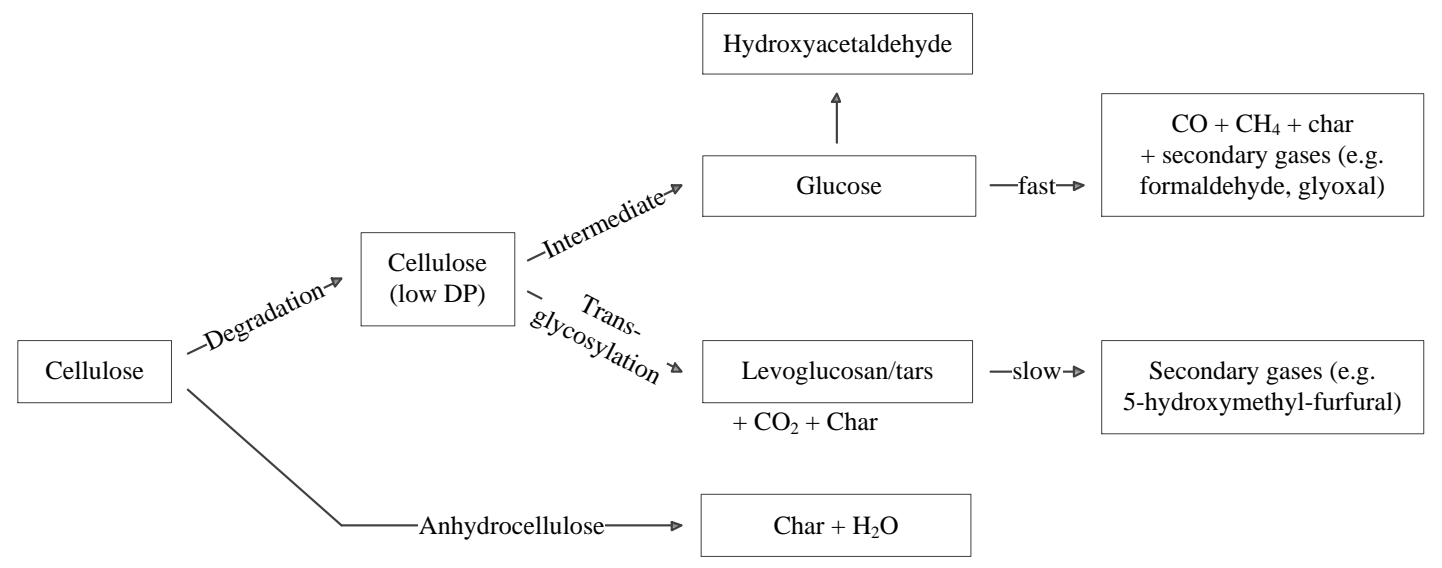

Figure 3. The reaction scheme for cellulose pyrolysis proposed in this work.

\subsubsection{Cellulose degradation pathway}

Following this pathway (see Fig. 3), the solid cellulose sample degrades to smaller chain fragments by bond dissociation between cellobiose monomers. This process, also called depolymerisation or fragmentation, is modelled by using a sectional approach, see chapter 2.1. The degradation is completed when cellulose fragments with a low degree of polymerisation (here: the smallest BIN) are formed.

Our model considers each 1,4'- $\beta$-glycosidic bond within the chain as equal. Hence, each possible cleavage happens with the same probability. The easiest case is bond dissociation in the very middle of the chain. The chain, which is considered to be symmetric, degrades to two identical fragments of the next but smaller BIN species. The probability factor of this fragmentation is considered unity. If the chain breaks at any other position, both a fragment of the initial and one of a smaller BIN class is produced. The bigger chain fragment belongs to the size class of the initial BIN, whereas the smaller fragment is considered a fraction of a smaller BIN depending on the position of the chain break. The stoichiometric coefficient of the initial BIN product is calculated by identifying the bigger chain fragment, i.e. the remaining fraction of the initial BIN. The rest of the initial chain is quantified as fraction of a smaller BIN species. Hence, each possible bond dissociation leads to two distinctive products. Each pair of initial BIN and any smaller BIN is possible, whatever the position of bond dissociation within the chain is. Therefore, events leading to the same products but possessing different stoichiometric coefficients are possible. These are summed up to one reaction in the mechanism with a normalised stoichiometric coefficient of unity for the reactant, and with the respective stoichiometric coefficients for the products.

The probability factor of each (summed up) reaction depends on the number of possibilities with the same product distribution. Since the chain is considered symmetric, the probability factor of each bond dissociation, except for the one happening in the very middle of the chain, is at least of the value of two. The highest probability factors are obtained for bond dissociation leading to the outcome of both initial and next, but smaller, BIN. Our model takes these reaction probability factors into account by multiplying it with the initial reaction rate coefficient of cellulose degradation.

Various kinetic data sets were investigated in building our reaction mechanism. The global reaction rate set for cellulose pyrolysis from Saddawi et al. [49], i.e. $A=2.2 \cdot 10^{13} \mathrm{~s}^{-1}$ and $E_{A}=178.7 \mathrm{~kJ} / \mathrm{mol}$, seems the most appropriate for cellulose degradation. However, the initiation of cellulose pyrolysis was predicted too early in our simulations using the values mentioned above. This might be due to the fact that our model does not treat cellulose as a lumped species. Therefore, we used the pre-exponential factor of Saddawi et al., i.e. $A=2.2 \cdot 10^{13} \mathrm{~s}^{-1}$, for the dissociation of one single 1,4'- $\beta$-glycosidic bond within the cellulose chain. According to the probability of each chain fragmentation reaction, we had to modify this value and hence the reaction rate coefficient of Saddawi et al. Furthermore, we propose a higher activation energy, i.e. $225.9 \mathrm{~kJ} / \mathrm{mol}$, which is closer to the values of Várhegyi, Antal and co-workers, i.e. $238 \mathrm{~kJ} / \mathrm{mol}[40,42]$. However, it is important to note that these authors report a higher pre-exponential factor in the range $10^{17}$ to $10^{18}$. Recently, our kinetic data set was confirmed (within the uncertainty limits) by quantum chemical calculations by Mayes and Broadbelt [50]. These authors report values of $A=4.7 \cdot 10^{13} \mathrm{~s}^{-1}$ and $E_{A} \approx 231 \mathrm{~kJ} / \mathrm{mol}$ at $773 \mathrm{~K}$ for the concerted glycosidic cleavage of methyl-cellobiose 
(initiation) at the M06-2X/6-311+G(3df,2p)//M06-2X/6-31+G(2df,p) level of theory.

\subsubsection{Anhydrocellulose pathway}

Following this pathway, solid cellulose decomposes to water and anhydrocellulose (or anhydrosugars) before the latter eventually reacts to solid residues (char) (see Fig. 3). While the anhydrocellulose pathway is suggested by several authors, e.g. [36], its existence is, on the other hand, critically discussed in literature [31, 42-45]. Antal et al. concluded that, under usual pyrolysis conditions, the anhydrocellulose pathway is suppressed by the depolymerisation step [42]. Nevertheless, we decided to include it in our reaction scheme following the Waterloo model [31]. Piskorz et al. proposed that if it existed, it would be a low-temperature step which would not directly lead to the formation of light gases. Due to the lack of experimental data, this pathway directly produces char and water in our model.

\subsubsection{Cellulose (low DP) devolatilisation scheme}

Various authors have pointed out that levoglucosan does not directly lead to the formation of formaldehyde and hydroxyacetaldehyde (glycolaldehyde) [30-33, 43]. Furthermore, these authors conclude that $\mathrm{CO}_{\text {and }} \mathrm{CO}_{2}$ are not produced from the same pathway. Hence, the devolatilisation scheme for cellulose with a low degree of polymerisation (DP) is distinguished in two competing pathways, as proposed e.g. in the Waterloo model [31]. Both pathways eventually lead to the formation of secondary gases. For this purpose, the work of Ranzi et al. provides a reasonable source [2]. However, we took into account various modifications based on [30-33, 43].

\subsubsection{Intermediate pathway}

The intermediate step proposed in literature [39, 43] is similar to the production of active cellulose in the Broido-Shafizadeh model. This high-temperature pathway is based on the idea of summarising several rapid, subsequent decomposition steps which are hardly detectable in experiments [43].

Richards observed hydroxyacetaldehyde during cellulose pyrolysis and claimed that it is not formed from the decomposition of levoglucosan [33] which is in agreement with our reaction scheme. Furthermore, Piskorz and co-workers $[31,32]$ concluded that glucose ring cracking reactions are responsible for the formation of hydroxyacetaldehyde (see Fig. 2). On the other hand, Mamleev et al. reported that CO and formaldehyde as well as char are formed by a fast reaction from the intermediate glucose [45]. This is in agreement with the work of Banyasz et al. who concluded that formaldehyde is a secondary product from the intermediate pathway [43].

In our model, we chose glucose as the intermediate species due to the chain structure of cellulose, and the cellobiose molecule respectively. Furthermore, glucose showed the expected decomposition products (hydroxyacetaldehyde as well as formaldehyde and carbon monoxide) as pointed out by Banyasz et al. [43]. The same intermediate species was chosen by Bouchard et al. [34, 35], and Mamleev et al. [45].

\subsubsection{Transglycosylation pathway}

Transglycosylation leads predominantly to the formation of tar species (levoglucosan), e.g. [45], as well as $\mathrm{CO}_{2}$ and char (see Fig. 3). This reaction pathway is of particular importance in the low-temperature regime. In an early work, Byrne et al. concluded that levoglucosan is not the source of formaldehyde, and acetaldehyde respectively [30]. Levoglucosan further decomposes to secondary products such as 5-hydroxymethyl-furfural $\left(\mathrm{C}_{6} \mathrm{H}_{6} \mathrm{O}_{3}\right)$ and dilactide $\left(\mathrm{C}_{6} \mathrm{H}_{8} \mathrm{O}_{4}\right)$ [2].

The thermochemical properties for the reaction products in our mechanism are taken from the thermodynamic database from Burcat and co-workers [51].

\section{Results}

\subsection{Simulations}

Simulations were performed using the chemical kinetics software Cantera [52]. Cellulose pyrolysis was investigated by well-stirred reactor simulations at constant atmospheric pressure. The solid sample enters the reactor with an initial temperature of $323 \mathrm{~K}$. Under a constant heating rate of 1,15 , or $150 \mathrm{~K} / \mathrm{min}$ as well as $10 \mathrm{~K} / \mathrm{min}$ respectively, cellulose is heated to a preset final temperature of $1073 \mathrm{~K}$ in order to reach the steady state. This is 
due to reports claiming that cellulose decomposition is completed at around $875 \mathrm{~K} \mathrm{[3]} \mathrm{or} \mathrm{even} \mathrm{lower} \mathrm{[42].} \mathrm{The}$ influence of the heating rate on cellulose pyrolysis reported in the literature, e.g. [42], was taken into account by using the respective temperature-time profiles. If not indicated differently in the text, the species concentrations reported here are in mass percentage.

Usually, the pyrolysis of cellulose is experimentally investigated by thermogravimetric analysis (TGA). Due to systematic errors, a thermal lag between the constantly increased reactor temperature and the actual sample temperature exists $[41,42,48]$. This effect is taken into account by using the latter temperature in our model. As proposed by Y. C. Lin et al. [48], and Monasse and Haudin [53], it is modelled by

$$
T_{\text {sample }}(t)=T_{0}+\beta \cdot(t-C)
$$

with the constant heating rate $\beta$ and the proportionality constant $C=7.86 \mathrm{~s}$. This value was experimentally determined by Y. C. Lin et al. [48]. It is worth mentioning that these authors propose another, physically more realistic thermal-lag model considering the heat transfer at the boundary of the cellulose sample as well as the heat flow by the endothermic pyrolysis. However, both of their kinetic data sets obtained from those two different thermal-lag approaches do only slightly differ.

\subsection{Results}

\subsubsection{Comparison with experiments from Y. C. Lin et al. [48]}

Y. C. Lin et al. [48] pyrolysed cellulose samples within a particle diameter range of 50 to $110 \mu \mathrm{m}$ at constant atmospheric pressure and measured the species concentrations using the TGA technique. Entering the reactor at an initial temperature of $323 \mathrm{~K}$, the samples were constantly heated with rates of 1,15 , and $150 \mathrm{~K} / \mathrm{min}$ respectively up to a final temperature of $1073 \mathrm{~K}$. They report initiation temperatures of cellulose pyrolysis of around 500, 550, and $600 \mathrm{~K}$ for those three heating rates. In comparison, our simulations with a comparable starting material of $\mathrm{BIN}_{18}$ show an offset of around $25 \mathrm{~K}$ to higher temperatures (see Fig. 4a). Both experiments and simulations show that low heating rates lead to lower pyrolysis initiation temperatures. This is due to the fact that slow subprocesses of pyrolysis at lower temperatures require a sufficient reaction time which is only provided during slow heating.

In our simulations, the temperature at which half the solid mass is decomposed, which we chose as a reference point, is shifted to lower temperatures by approximately $25 \mathrm{~K}$ for the low heating rate, and $8 \mathrm{~K}$ for the medium heating rate, whereas it is in perfect agreement for the high heating rate (see Fig. 4a). However, it can be observed

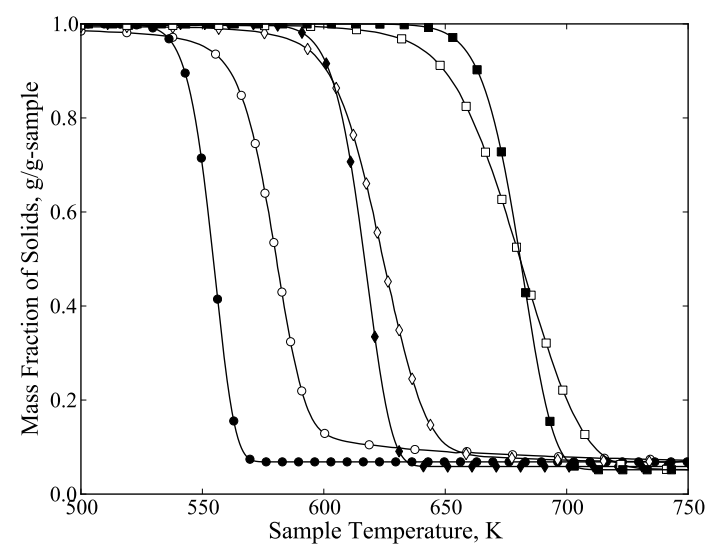

(a) Heating rates: $1,15,150 \mathrm{~K} / \mathrm{min}$

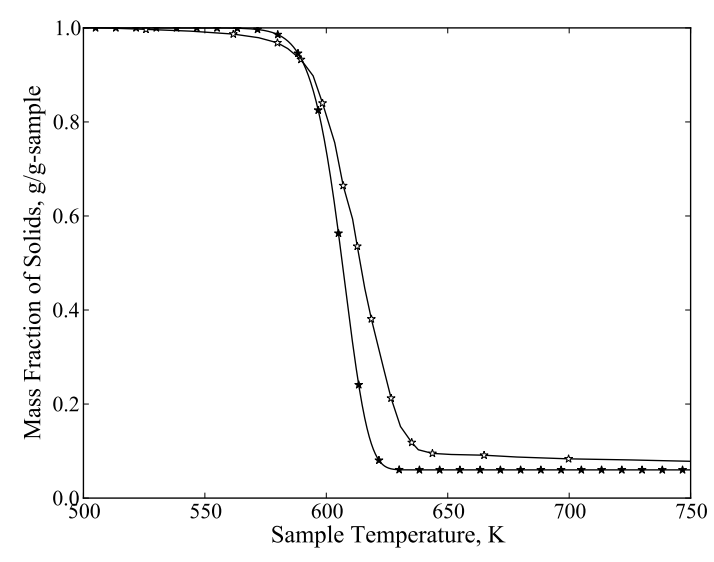

(b) Heating rate: $10 \mathrm{~K} / \mathrm{min}$

Figure 4. Cellulose Pyrolysis: Mass fraction of solids as a function of reactor temperature. Atmospheric pressure, $T_{0}=323 \mathrm{~K}, T_{\text {end }}=1073 \mathrm{~K}$. (a) Simulations: full symbols, experiments [48]: open symbols. Sample size: $110 \mu \mathrm{m}$ (三 BIN 18 ), heating rates: $1 \mathrm{~K} / \mathrm{min}$ (circles), $15 \mathrm{~K} / \mathrm{min}$ (diamonds), $150 \mathrm{~K} / \mathrm{min}$ (squares). (b) Simulations: full symbols, experiments [4]: open symbols. Sample size: $74 \mu \mathrm{m}\left(\equiv \mathrm{BIN}_{17}\right)$, heating rate: $10 \mathrm{~K} / \mathrm{min}$ (stars). 
that our simulation curves have too steep a gradient for the medium and high heating rates. Modifying the basic kinetic data set for the cellulose degradation reactions by changing the pre-exponential Arrhenius factor can reduce this effect. On the other hand, those modifications result in larger temperature shifts to even lower temperatures at the reference point.

In their experiments, Y. C. Lin et al. obtained decreasing yields of solid residues (char) for increasing heating rates, i.e. $6.3 \%(1 \mathrm{~K} / \mathrm{min}), 6.1 \%(15 \mathrm{~K} / \mathrm{min})$, and $4.6 \%(150 \mathrm{~K} / \mathrm{min})$ [48]. The well known fact that slow heating rates lead to a higher production of char is also confirmed by our simulations. The final char concentrations are very well predicted with values of $6.9 \%(1 \mathrm{~K} / \mathrm{min}), 5.9 \%(15 \mathrm{~K} / \mathrm{min})$, and $5.2 \%(150 \mathrm{~K} / \mathrm{min})$.

Apart from that, it is worth mentioning that the mechanisms of char production from cellulose pyrolysis are still debated in literature [2, 42, 48].

Figure 5 shows product distribution profiles as a function of reactor residence time for different heating rates $(1,15,150$, and $10 \mathrm{~K} / \mathrm{min}$ respectively). One observes the following: After the reactor is heated to the pyrolysis initiation temperature, the cellulose sample degrades rapidly and at nearly the same time the devolatilisation of cellulose with a low degree of polymerisation begins. Tars (including levoglucosan), water, $\mathrm{CO}, \mathrm{CO}_{2}$ and solid residues (char) are formed. The production of glucose is not observable here (maximum concentrations in the range of $10^{-5}$ ). This is attributed to the very rapid production and decomposition of glucose during the intermediate pathway mentioned in Chapter II.B.4. After the cellulose decomposition is completed and close to the time when the tars production reaches its peak, secondary gas-phase reactions start. They produce, on the one hand, a decline in tars (especially levoglucosan), but on the other hand a rise in water. Interestingly, they do not effect the char production. After the reactor is heated to a sufficiently high temperature, the steady state is reached. For clarity purposes, secondary gases were not included in Fig. 5.

The influence of heating rate on cellulose pyrolysis can clearly be observed in Fig. 5. Cellulose pyrolysis requires shorter reaction times with increasing heating rates, i.e. pyrolysis initiation time as well as the actual process duration. Although, the order of magnitude of the heating rate can be directly correlated with the order of magnitude of the residence time, it is important to note that it has neither a direct quantitative correlation to the time when the pyrolysis is initiated nor to the pyrolysis duration. It can be observed from Fig. 5a-5c that cellulose (even with low DP) decomposition is completed at temperatures of approximately $575 \mathrm{~K}(1 \mathrm{~K} / \mathrm{min})$, $650 \mathrm{~K}(15 \mathrm{~K} / \mathrm{min})$, and $710 \mathrm{~K}(150 \mathrm{~K} / \mathrm{min})$. Moreover, the steady state of its gaseous products is reached at around 630,750 , and $840 \mathrm{~K}$ for the same heating rates.

Increasing the heating rate also has a huge influence on the product yields. The final tars concentration decreases with increasing heating rate. Levoglucosan as the major tars component [3] is additionally included in Fig. 5. As expected, it shows the same decreasing behaviour as the total tars. It is interesting to note that the tars peaks do not change significantly with increasing heating rate. $\mathrm{CO}_{2}$ which is also produced from the transglycosylation pathway also decreases with increasing heating rate, whereas $\mathrm{CO}$, the only species exclusively produced from the intermediate pathway shown in Fig. 5, increases. All these observations are consistent with our reaction scheme which claims that the intermediate pathway (characterised as fast) is important at high temperatures and the transglycosylation pathway (characterised as slow) at low temperatures. The yields for water and char, species not directly related to one reaction pathway, decrease with increasing heating rate.

\subsubsection{Comparison with experiments from Worasuwannarak and co-workers [3, 4]}

The second experimental data set which we compared with our simulations was a coupled TGA and MS pyrolysis experiment with dried cellulose by Worasuwannarak and co-workers [3, 4] (see Fig. 4b and Fig. 5d). Samples of less than $74 \mu \mathrm{m}$ in diameter were pyrolysed at a constant heating rate of $10 \mathrm{~K} / \mathrm{min}$. Secondary reactions were experimentally ruled out. These authors report the products of cellulose decomposition at the final designated temperature of $873 \mathrm{~K}$ to $67.6 \%$ tars, and approximately $13 \% \mathrm{H}_{2} \mathrm{O}, 7 \%$ char, $5 \% \mathrm{CO}, 5 \% \mathrm{CO}_{2}$ as well as negligible quantities of $\mathrm{H}_{2}$ and $\mathrm{CH}_{4}$. It is important to note that they only measured the above mentioned species excluding tars (levoglucosan). However, they defined the "tars" yield as the remaining, non-measured mass percentage. This is a entirely different approach compared to the common literature. It is also in disagreement with our reaction scheme claiming that levoglucosan is only produced from one of the two competing decomposition pathways of cellulose with a low degree of polymerisation.

Figure $4 \mathrm{~b}$ illustrates the comparison between experiments and simulations for the concentration of solids over (sample) temperature at a heating rate of $10 \mathrm{~K} / \mathrm{min}$. We selected $\mathrm{BIN}_{17}$ as starting material since the experimental sample size of $74 \mu \mathrm{m}$ falls into the mass range covered by this transient species. The slopes of both curves are 

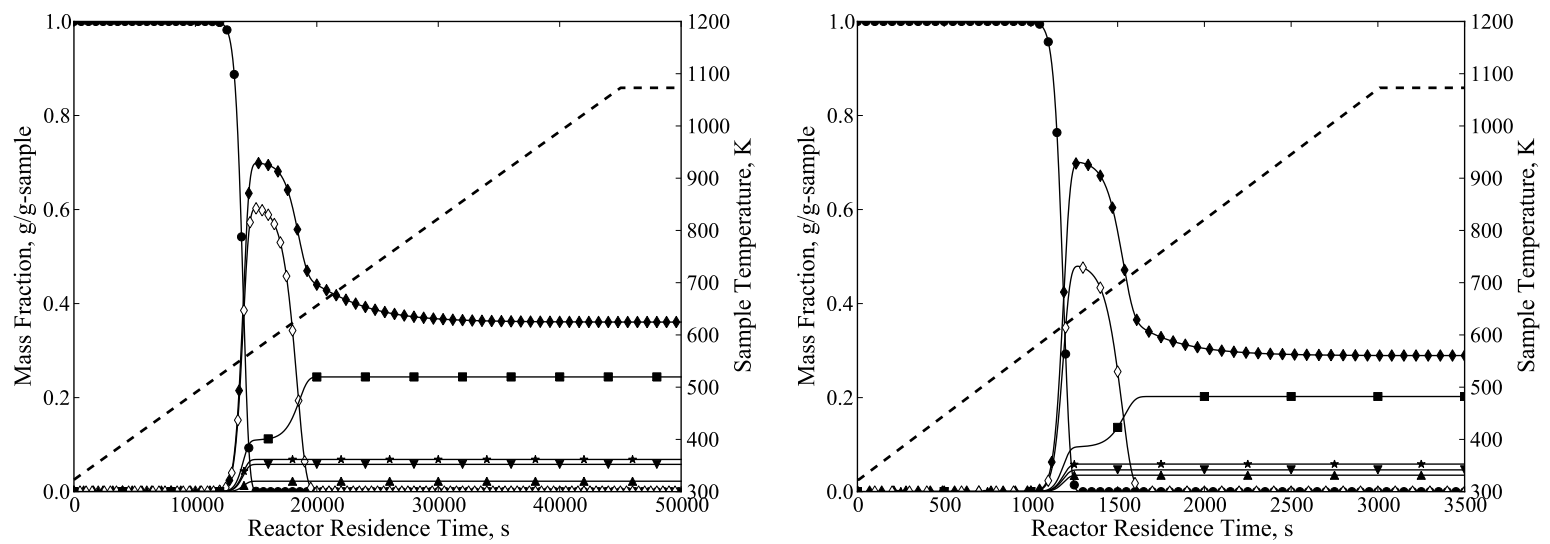

(a) Heating rate: $1 \mathrm{~K} / \mathrm{min}$

(b) Heating rate: $15 \mathrm{~K} / \mathrm{min}$

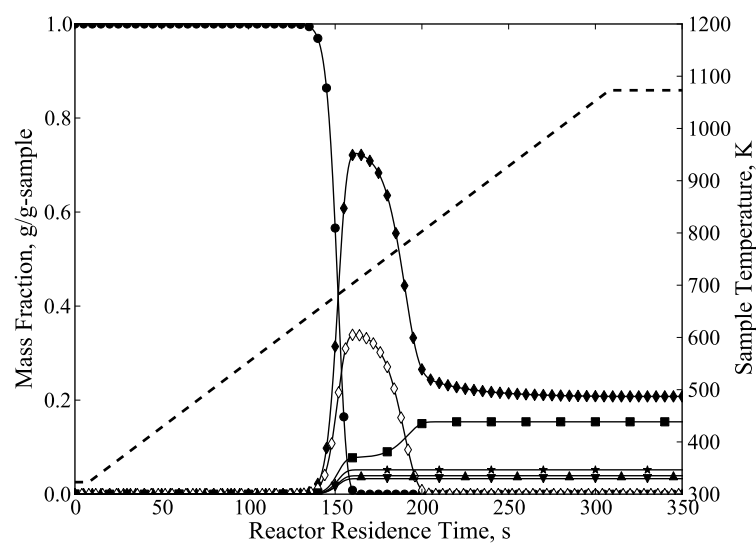

(c) Heating rate: $150 \mathrm{~K} / \mathrm{min}$

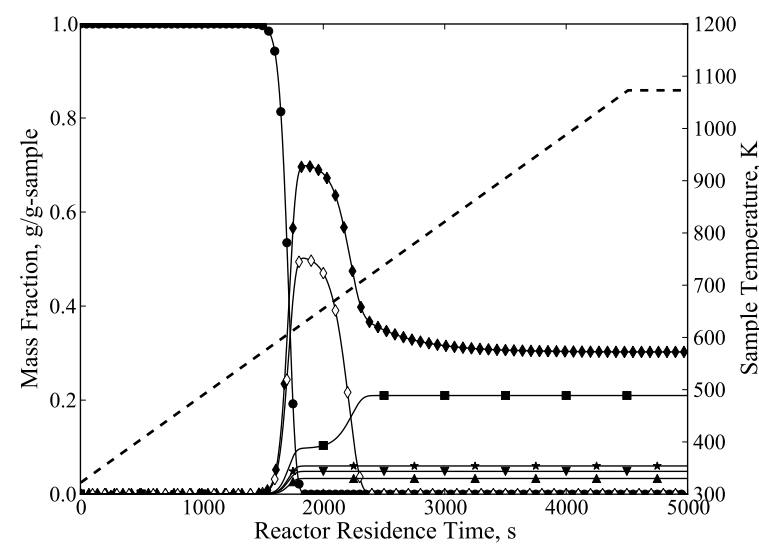

(d) Heating rate: $10 \mathrm{~K} / \mathrm{min}$

Figure 5. Cellulose pyrolysis: Mass fractions and reactor temperature as a function of reactor residence time. Atmospheric pressure, $T_{0}=323 \mathrm{~K}, T_{\text {end }}=1073 \mathrm{~K}$. Heating rates: (a) $1 \mathrm{~K} / \mathrm{min}$, (b) $15 \mathrm{~K} / \mathrm{min}$, (c) $150 \mathrm{~K} / \mathrm{min}$, (d) $10 \mathrm{~K} / \mathrm{min}$. Starting material: (a)-(c) $\mathrm{BIN}_{18}$, (d) $\mathrm{BIN}_{17}$. Cellulose: circles, tars: diamonds (full), levoglucosan: diamonds (open), water: squares, solid residues (char): stars, $\mathrm{CO}$ : triangles up, $\mathrm{CO}_{2}$ : triangles down, temperature: dashed line.

in good agreement which is consistent with the first experimental data set (for lower heating rates). However, the simulated temperature regime between pyrolysis initiation and steady state of char production is too small. For the above mentioned reference point of $50 \%$ solids, a temperature offset of less than $10 \mathrm{~K}$ is observed.

Figure 5d shows the simulated species concentrations during cellulose pyrolysis. Our simulations show good agreement in terms of final char $(6.0 \%)$ and $\mathrm{CO}_{2}(4.9 \%)$ yield. However, the final concentrations of $\mathrm{CO}(3.3 \%)$ and the particular overestimation of water $\left(21.0 \%\right.$ ) are unsatisfactory. The final concentrations of $\mathrm{H}_{2}$ and $\mathrm{CH}_{4}$ (not shown in Fig. 5d) were also negligible in our simulations. As indicated above, the actual tars yield cannot be compared directly. However, the remaining mass percentage of the "non-measured species" (64.8\%) is in good agreement with their result. 


\section{Conclusions}

A new reaction scheme for the pyrolysis of cellulose is presented. Its single reaction pathways are based on various models from literature. However, the degradation (depolymerisation) step of solid cellulose is described by a sectional model approach. In our model, the longitudinal structure of cellulose is described as chains consisting of cellobiose building blocks. Cellulose is grouped into several transient species (BINs) which cover particular chain fragment sizes (and therefore mass ranges) depending on the number of those cellobiose units. To the authors' knowledge, the sectional approach has so far not been adapted to the pyrolysis of cellulose. In decomposition models from literature, cellulose is often characterized as a lumped species. However, it is known that the properties of cellulose depend on chain length, i.e. number of monomers. By introducing pseudo species (BINs) to the degradation pathway of the reaction scheme, we were able to describe the phase transition from solid cellulose samples via cellulose with a low degree of polymerisation (DP) to products in the gas-phase during pyrolysis. Our reaction scheme comprises the degradation of (solid) cellulose and its direct decomposition to char, the devolatilisation of cellulose with low DP (including transglycosylation and the formation of the intermediate glucose), and secondary gas-phase reactions. For the cellulose degradation pathway, we propose the following kinetic data set: $A=2.2 \cdot 10^{13} \mathrm{~s}^{-1}$ and $E_{A}=225.9 \mathrm{~kJ} / \mathrm{mol}$ for the dissociation of one single $1,4^{\prime}-\beta$-glycosidic bond within the cellulose chain, a set recently confirmed by Mayes and Broadbelt [50].

Compared with two different experimental data sets for various heating rates $(1,15,150$, and $10 \mathrm{~K} / \mathrm{min}$ respectively), our simulations show good agreement. The influence of the heating rate on the results is clearly shown in terms of pyrolysis initiation time, pyrolysis duration and products yield. Furthermore, it confirms general trends from our reaction scheme, especially from the competing devolatilisation pathways. Apart from water final concentrations of the primary decomposition products are well captured. It has been observed that the definition of tar species is not always consistent in literature. Due to this inconsistency, comparisons between different results must be scrutinised. Moreover, our model requires validation against further experimental data. However, the validation for the practical case of fast pyrolysis with heating rates of approximately $1000 \mathrm{~K} / \mathrm{min}$ is not possible until experimental data for those conditions are available in literature.

There are two promising modifications which we will implement in the near future in order to enhance our model. First, the integration of the initial conversion step of cellulose from a crystalline to an amorphous structure at lower temperatures confirmed by the Auerbach group [15]. And second, the more detailed investigation of the secondary reaction pathways including the enhancement of the small molecule chemistry.

Our objective is to develop a global model for the thermal decomposition of lignocellulosic biomass. In addition to the presented cellulose submodel, submodels for the pyrolysis of both hemicellulose and lignin need to be developed. However, these biomass components possess many fewer uniform polymer structures and to some extent even random alignments. For instance, hemicellulose is a general term for several connected polysaccharides (e.g. xylan, xyloglucan) consisting of even different sugar monomers (e.g. glucose, xylose, mannose). Moreover, a global biomass pyrolysis model needs to take into account the diversified component quantities of different types of lignocellulosic biomass. Another problem is the high influence of the interconnection between the single submodels on the product distribution. For instance, levoglucosan, the main product of cellulose pyrolysis, is only found in typical quantities of around $5 \%$ at the pyrolysis of lignocellulosic biomass. This is due to the interaction behaviour between cellulose and lignin, as reported e.g. in [3]. Therefore, not only the submodels for the main components but the global scheme for lignocellulosic biomass has to be validated against experimental data to take into account the interaction phenomena.

\section{References}

[1] Energy research Centre of the Netherlands, Phyllis, database for biomass and waste, URL: http: //www.ecn.nl/phyllis, [cited 15 April 2013].

[2] Ranzi, E., Cuoci, A., Faravelli, T., Frassoldati, A., Migliavacca, G., Pierucci, S., and Sommariva, S., "Chemical Kinetics of Biomass Pyrolysis", Energy and Fuels Vol. 22 (6) (2008) pp. 4292-4300.

[3] Worasuwannarak, N., Sonobe, T., and Tanthapanichakoon, W., "Pyrolysis Behaviors of Rice Straw, Rice Husk, and Corncob by TG-MS Technique", Journal of Analytical and Applied Pyrolysis Vol. 78 (2007) pp. 265-271. 
[4] Sonobe, T., and Worasuwannarak, N., "Kinetic Analyses of Biomass Pyrolysis Using the Distributed Activation Energy Model", Fuel Vol. 87 (3) (2008) pp. 414-421.

[5] Montross, M., and Crofcheck, C., "Energy Crops for the Production of Biofuels", in: M. Crocker (Ed.), Thermochemical Conversion of Biomass to Liquid Fuels and Chemicals, RSC Energy and Environment Series No. 1, RSC Publishing, Cambridge, England, UK, 2010, pp. 26-45.

[6] Biagini, E., Barontini, F., and Tognotti, L., "Devolatilization of Biomass Fuels and Biomass Components Studied by TG/FTIR Technique", Industrial \& Engineering Chemistry Research Vol. 45 (2006) pp. 4486-4493.

[7] Mohan, D., Pittman, C. U., and Steele, P. H., "Pyrolysis of Wood/Biomass for Bio-oil: A Critical Review", Energy and Fuels Vol. 20 (3) (2006) pp. 848-889.

[8] Di Blasi, C., "Modeling Chemical and Physical Processes of Wood and Biomass Pyrolysis", Progress in Energy and Combustion Science Vol. 34 (2008) pp. 47-90.

[9] Crocker, M., and Andrews, R., "The Rationale for Biofuels", in: M. Crocker (Ed.), Thermochemical Conversion of Biomass to Liquid Fuels and Chemicals, RSC Energy and Environment Series No. 1, RSC Publishing, Cambridge, England, UK, 2010, pp. 1-25.

[10] Bridgwater, A. V., "Fast Pyrolysis of Biomass for Energy and Fuels", in: M. Crocker (Ed.), Thermochemical Conversion of Biomass to Liquid Fuels and Chemicals, RSC Energy and Environment Series No. 1, RSC Publishing, Cambridge, England, UK, 2010, pp. 146-191.

[11] Calonaci, M., Grana, R., Barker Hemings, E., Bozzano, G., Dente, M., and Ranzi, E., "Comprehensive Kinetic Modeling Study of Bio-oil Formation from Fast Pyrolysis of Biomass", Energy and Fuels Vol. 24 (10) (2010) pp. 5727-5734.

[12] Guha, S. K., Kobayashi, H., and Fukuoka, A., "Conversion of Cellulose to Sugars", in: M. Crocker (Ed.), Thermochemical Conversion of Biomass to Liquid Fuels and Chemicals, RSC Energy and Environment Series No. 1, RSC Publishing, Cambridge, England, UK, 2010, pp. 344-364.

[13] Sugiyama, J., Persson, J., and Chanzy, H., "Combined Infrared and Electron Diffraction Study of the Polymorphism of Native Celluloses", Macromolecules Vol. 24 (9) (1991) pp. 2461-2466.

[14] Sugiyama, J., Vuong, R., and Chanzy, H., "Electron Diffraction Study on the Two Crystalline Phases Occurring in Native Cellulose from an Algal Cell Wall", Macromolecules Vol. 24 (14) (1991) pp. 4168-4175.

[15] Agarwal, V., Huber, G. W., Conner, W. C., and Auerbach, S. M., "Simulating Infrared Spectra and Hydrogen Bonding in Cellulose I $\beta$ at Elevated Temperatures", The Journal of Chemical Physics Vol. 135 (13) (2011) 134506.

[16] Haworth, W. N., and Hirst, E. L., "XXII. - The Constitution of the Disaccharides. Part V. Cellobiose (Cellose)", Journal of the Chemical Society, Transactions Vol. 119 (1921) pp. 193-201.

[17] Haworth, W. N., Hirst, E. L., and Thomas, H. A., "The Existence of the Cellobiose Residue in Cellulose", Nature Vol. 126 (1930) p. 438.

[18] Assary, R. S., and Curtiss, L. A., "Thermochemistry and Reaction Barriers for the Formation of Levoglucosenone from Cellobiose", ChemCatChem Vol. 4 (2) (2012) pp. 200-205.

[19] Gelbard, F., Tambour, Y., and Seinfeld, J. H., "Sectional Representations for Simulating Aerosol Dynamics", Journal of Colloid and Interface Science Vol. 76 (1980) pp. 541-556.

[20] Pope, C. J., and Howard, J. B., "Simultaneous Particle and Molecule Modeling (SPAMM): An Approach for Combining Sectional Aerosol Equations and Elementary Gas-Phase Reactions", Aerosol Science and Technology Vol. 27 (1997) pp. 73-94.

[21] Kronholm, D. F., "Molecular Weight Growth Pathways in Fuel-Rich Combustion", Ph.D. Dissertation, Department of Chemical Engineering, Massachusetts Institute of Technology, Cambridge, MA, USA (2000).

[22] Wen, J. Z., Thompson, M. J., Park, S. H., Rogak, S. N., and Lightstone, M. F., "Study of Soot Growth in a Plug Flow Reactor Using a Moving Sectional Model", in: Proceedings of the Combustion Institute, Vol. 30, The Combustion Institute, 2005, pp. 1477-1484. 
[23] Blacha, T., Di Domenico, M., Gerlinger, P., and Aigner, M., "Soot Modeling in Partially Premixed $\mathrm{C}_{2} \mathrm{H}_{4} /$ Air Flames", $48^{\text {th }}$ AIAA Aerospace Sciences Meeting Including the New Horizons Forum and Aerospace Exposition (2010 (1)) AIAA Paper 2010-1516.

[24] Kilzer, F. J., and Broido, A., "Speculations on the Nature of Cellulose Pyrolysis", Pyrodynamics Vol. 2 (1965) pp. 151163.

[25] Broido, A., and Weinstein, M., "Low Temperature Isothermal Pyrolysis of Cellulose", in: H. G. Wiedemann (Ed.), Pro-

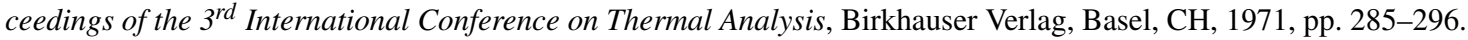

[26] Broido, A., and Nelson, M. A., "Char Yield on Pyrolysis of Cellulose", Combustion and Flame Vol. 24 (1975) pp. 263268.

[27] Broido, A., "Kinetics of Solid-Phase Cellulose Pyrolysis", in: Shafizadeh, F., Sarkanen, K., and Tillman, D. A. (Ed.), Thermal Uses and Properties of Carbohydrates and Lignins, Academic Press, New York, USA, 1976, pp. 19-36.

[28] Shafizadeh, F., and Chin, P. P. S., "Thermal Deterioration of Wood", in: I. S. Goldstein (Ed.), Wood Technology: Chemical Aspects, ACS Symposium Series, Vol. 43, American Chemical Society, Washington, D.C., USA, 1977, Ch. 5, pp. 57-81.

[29] Bradbury, A. G. W., Sakai, Y., and Shafizadeh, F., "A Kinetic Model for Pyrolysis of Cellulose", Journal of Applied Polymer Science Vol. 23 (11) (1979) pp. 3271-3280.

[30] Byrne, G. A., Gardiner, D., and Holmes, F. H., "The Pyrolysis of Cellulose and the Action of Flame-retardants - II. Further Analysis and Identification of Products", Journal of Applied Chemistry Vol. 16 (3) (1966) pp. 81-88.

[31] Piskorz, J., Radlein, D., and Scott, D. S., "On the Mechanism of the Rapid Pyrolysis of Cellulose", Journal of Analytical and Applied Pyrolysis Vol. 9 (1986) pp. 121-137.

[32] Radlein, D., Piskorz, J., and Scott, D. S., "Fast Pyrolysis of Natural Polysaccharides as a Potential Industrial Process", Journal of Analytical and Applied Pyrolysis Vol. 19 (1991) pp. 41-63.

[33] Richards, G. N., "Glycolaldehyde from Pyrolysis of Cellulose", Journal of Analytical and Applied Pyrolysis Vol. 10 (3) (1987) pp. 251-255.

[34] Bouchard, J., Abatzoglou, N., Chornet, E., and Overend, R. P., "Characterization of Depolymerized Cellulosic Residues - Part 1: Residues Obtained by Acid Hydrolysis Processes", Wood Science and Technology Vol. 23 (1989) pp. 343-355.

[35] Bouchard, J., Gamier, G., Vidal, P., Chornet, E., and Overend, R. P., "Characterization of Depolymerized Cellulosic Residues - Part 2: Residues Derived from Ethylene Glycol Solvolysis of Cellulose", Wood Science and Technology Vol. 24 (1990) pp. 159-169.

[36] Diebold, J. P., "A Unified, Global Model for the Pyrolysis of Cellulose", Biomass and Bioenergy Vol. 7 (1994) pp. $75-85$.

[37] Milosavljevic, I., and Suuberg, E. M., "Cellulose Thermal Decomposition Kinetics: Global Mass Loss Kinetics", Industrial \& Engineering Chemistry Research Vol. 34 (1995) pp. 1081-1091.

[38] Conesa, J. A., Caballero, J. A., Marcilla, A., and Font, R., "Analysis of Different Kinetic Models in the Dynamic Pyrolysis of Cellulose", Thermochimica Acta Vol. 254 (1995) pp. 175-192.

[39] Várhegyi, G., Szabó, P., Shu-Lai Mok, W., and Antal Jr., M. J., "Kinetics of the Thermal Decomposition of Cellulose in Sealed Vessels at Elevated Pressures. Effects of the Presence of Water on the Reaction Mechanism", Journal of Analytical and Applied Pyrolysis Vol. 26 (3) (1993) pp. 159-174.

[40] Várhegyi, G., Jakab, E., and Antal Jr., M. J., "Is the Broido-Shafizadeh Model for Cellulose Pyrolysis True?", Energy and Fuels Vol. 8 (1994) pp. 1345-1352.

[41] Várhegyi, G., Antal Jr., M. J., Jakab, E., and Szabó, P., "Kinetic Modeling of Biomass Pyrolysis", Journal of Analytical and Applied Pyrolysis Vol. 42 (1997) pp. 73-87.

[42] Antal Jr., M. J., Várhegyi, G., and Jakab, E., "Cellulose Pyrolysis Kinetics: Revisited", Industrial \& Engineering Chemistry Research Vol. 37 (1998) pp. 1267-1275.

[43] Banyasz, J. L., Li, S., Lyons-Hart, J. L., and Shafer, K. H., "Cellulose Pyrolysis: The Kinetics of Hydroxyacetaldehyde Evolution", Journal of Analytical and Applied Pyrolysis Vol. 57 (2001) pp. 223-248. 
[44] Banyasz, J. L., Li, S., Lyons-Hart, J. L., and Shafer, K. H., "Gas Evolution and the Mechanism of Cellulose Pyrolysis", Fuel Vol. 80 (2001) pp. 1757-1763.

[45] Mamleev, V., Bourbigot, S., and Yvon, J., "Kinetic Analysis of the Thermal Decomposition of Cellulose: The Change of the Rate Limitation", Journal of Analytical and Applied Pyrolysis Vol. 80 (2007) pp. 141-150.

[46] Mamleev, V., Bourbigot, S., and Yvon, J., "Kinetic Analysis of the Thermal Decomposition of Cellulose: The Main Step of Mass Loss", Journal of Analytical and Applied Pyrolysis Vol. 80 (2007) pp. 151-165.

[47] Mamleev, V., Bourbigot, S., Le Bras, M., and Yvon, J., "The Facts and Hypotheses Relating to the Phenomenological Model of Cellulose Pyrolysis: Interdependence of the Steps", Journal of Analytical and Applied Pyrolysis Vol. 84 (2009) pp. 1-17.

[48] Lin, Y. C., Cho, J., Tompsett, G. A., Westmoreland, P. R., and Huber, G. W., "Kinetics and Mechanism of Cellulose Pyrolysis", Journal of Physical Chemistry C Vol. 113 (2009) pp. 20097-20107.

[49] Saddawi, A., Jones, J. M., Williams, A., and Wójtowicz, M. A., "Kinetics of the Thermal Decomposition of Biomass", Energy and Fuels Vol. 24 (2010) pp. 1274-1282.

[50] Mayes, H. B., and Broadbelt, L. J., "Unraveling the Reactions that Unravel Cellulose", The Journal of Physical Chemistry $A$ Vol. 116 (2012) pp. 7098-7106.

[51] Goos, E., Burcat, A., and Ruscic, B., "Extended Third Millennium Ideal Gas and Condensed Phase Thermochemical Database for Combustion with Updates from Active Thermochemical Tables", URL: http://www.dlr.de/vt/en/, [cited 15 April 2013].

[52] Goodwin, D., "Cantera: An Object-Oriented Software Toolkit for Chemical Kinetics, Thermodynamics, and Transport Processes", URL: http://code.google.com/p/cantera/ [cited 15 April 2013], Ver. 1.8.0, California Institute of Technology, Pasadena, CA, USA, 2009.

[53] Monasse, B., and Haudin, J. M., "Thermal Dependence of Nucleation and Growth Rate in Polypropylene by Nonisothermal Calorimetry", Colloid and Polymer Science Vol. 264 (2) (1986) pp. 117-122. 